\title{
As MUDANÇAS NO ARCABOUÇO LEGAL E A PRECARIZAÇÃO DO TRABALHO DOCENTE NO Estado de São Paulo durante o Governo dE José SERRA - PSDB (2007/2010)
}

\author{
The changes in the legal architecture and the precarization \\ of teaching work in the State ff São Paulo during the \\ government of José Serra - PSDB (2007/2010)
}

RESUmo Durante o período de 2007 a 2010, o governo de José Serra no Estado de São Paulo executou uma série de mudanças no conjunto da legislação estadual. Essas mudanças tiveram uma clara intenção de promover alterações nas relações de trabalho do funcionalismo público estadual, e especificamente dos servidores da educação e dos docentes. Nosso objetivo com este trabalho é demonstrar algumas das implicações dessas mudanças normativas na carreira docente. Partimos do pressuposto de que esse novo marco regulatório, inspirado no ideário neoliberal, se materializou numa profunda precarização do trabalho e na desconstrução da carreira docente no sistema de ensino público estadual. Por meio da análise da legislação, estamos identificando um forte movimento de degradação das condições sociais do trabalho com a retirada e/ou flexibilização dos direitos, o que tem contribuído para a configuração de um cenário de maior precariedade do trabalho e instabilidade no emprego para os docentes.

PALAVRAS-CHAVE: PRECARIZAÇÃO; TRABALHO DOCENTE; EDUCAÇÃO.

ABSTRACT During the period 2007-2010, the government of José Serra in the State São Paulo performed a series of changes throughout the State legislation. These changes had a clear intention to promote changes in work relationships of the civil state service and specifically the education officials and teachers. Our goal with this study is to demonstrate some of the implications of these changes in the teaching career. Assuming that this new regulatory framework, inspired by the neoliberal ideas, materialized in a deep precariousness of work and in the deconstruction of the teaching profession in the public state education system. Through the analysis of the legislation, we are identifying a strong movement degradation of social conditions of working with the removal and / or flexibility of rights which has contributed to setting up a scenario of greater job insecurity and instability in employment for teachers.

KEY-WORDS: PRECARIOUSNESS; TEACHING WORK; EDUCATION.

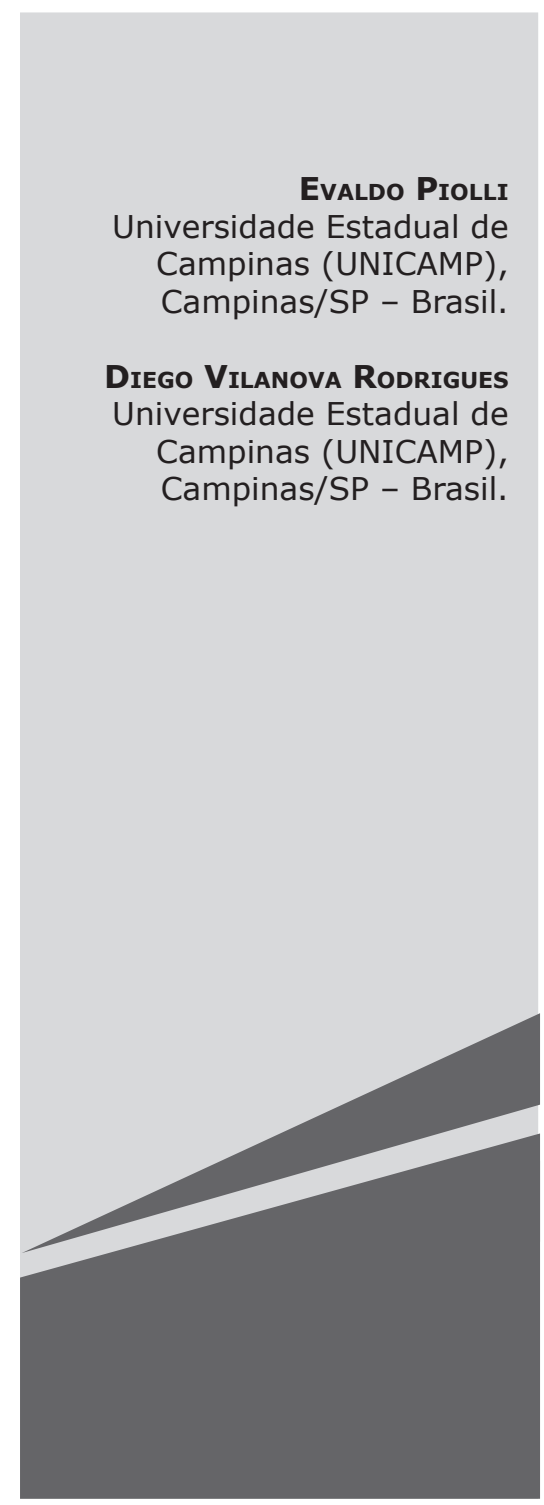




\section{INTRODUÇÃO}

A s políticas educacionais do governo do Estado de São Paulo, principalmente no período do governo de José Serra (2007-2010), e seus desdobramentos no trabalho dos docentes do ensino básico ${ }^{1}$ da rede estadual de ensino oficial do Estado de São Paulo, têm apontado para uma precariedade do trabalho e das condições de trabalho docente. A análise feita por diversos autores a respeito desses temas indica a infinidade de dimensões pelas quais podemos apreender essa relação, a saber: políticas educacionais dos governos e a intensificação e precarização do trabalho docente. Acerca das próprias políticas educacionais, das formas de financiamento da educação, do arcabouço ideológico sustentador e mantenedor de tais políticas e a consequente implicação destas na reorganização e/ou reestruturação do trabalho docente e no próprio processo de ensino/aprendizagem, para exemplificar podemos citar: Sanfelice (2010); Hypolito (2010); Callegari (2009); Costa e Souza (2009); Carvalho e Russo (2012). A apreensão dos próprios trabalhadores em educação e de suas formas de organização, bem como, dos atores sociais envolvidos, comparecem nas contribuições de Silva (2013) e Fernandes (2010). A precariedade e flexibilidade do trabalho docente e das condições de trabaIho, as suas consequências e manifestações (como adoecimento por doenças profissionais, frustração profissional, contratação precária, sobrecarga de trabalho, baixa remuneração, insuficiência material para o ofício do magistério, meritocracia, tecnocracia etc.), também têm merecido cada vez mais a atenção de pesquisadores que analisam a intrínseca relação entre o mundo do trabaIho e a Educação. Como: Oliveira (2004); Souza e Leite (2011); Lapo e Bueno (2002); Lelis (2012) e; Abonizio (2012).

Este trabalho se propõe, no entanto, a colaborar no preenchimento de uma lacuna existente no campo de estudo desse tema,

Professores e professoras que lecionam no Ensino Fundamental (Ciclo I e II) e Ensino Médio. que é o aprofundamento da análise dessa relação entre as políticas educacionais no Estado de São Paulo e a precariedade do trabalho e das condições sociais de trabalho docente durante o governo em questão entre os anos de 2007 e 2010, tendo como olhar principal a relação entre dados sobre a categoria e a análise da legislação aplicada no período.

A precarização do trabalho docente verificada em São Paulo conflui com o quadro amplo apontado por Oliveira (2004), quando analisa os efeitos das reformas educacionais sobre as relações de emprego dos professores. A autora aponta o aumento dos contratos temporários nas redes públicas de ensino, o crescente arrocho dos salários, o desrespeito ao piso nacional, a perda das garantias trabalhistas e previdenciárias, e a instabilidade e precariedade do emprego.

A precarização do trabalho é compreendida por nós como um processo histórico resultante das reformas neoliberais do Estado e das mutações ocorridas no mundo do trabalho, e que se expressam pela flexibilização da legislação, dos contratos e dos regulamentos sobre o trabalho. Como destacam Salerno (1995) e Alves (2007), essa flexibilização é estratégica e central para o processo de acumulação do capital em nosso contexto. A inserção dos trabalhadores no mercado de trabalho, nessas condições, segue acompanhada de maior insegurança e vulnerabilidade (CASTEL, 1998). Como os trabalhadores do setor produtivo, os efeitos quanto ao aspecto da insegurança para os professores se manifestam sobre os seguintes pontos: a) na redução crescente dos trabalhadores estáveis, frente aos trabalhadores temporários, eventuais ou, como no caso dos docentes contratados por tempo determinado; b) na insegurança relativa à renda que é produzida pela perda ou não acesso à estabilidade, direitos e garantias dos rendimentos do trabalho (ciclo de subemprego e desemprego); c) nos diferentes níveis de contratação que geram clivagens e a fragmentação da categoria profissional, produzindo efeitos diretos na organização coletiva e sindical. 


\section{A Lei Complementar 1.093/2009 E AS PROFUNDAS MUDANÇAS NA CARREIRA DOCENTE}

A Lei Complementar 1.093, de 16 de juIho de 2009, antigo Projeto de Lei Complementar (PLC) 19/2009, especificou as novas subcategorias de professores admitidos em caráter temporário, o categoria " $F$ " já existente, o categoria "L" em extinção com a aprovação dessa Lei e criou o categoria "O" submetido às normas do contrato de trabaIho, o qual o novo regramento determina, diferenciou o vínculo previdenciário, criou contrato de trabalho específico, além de regulamentar o processo seletivo simplificado para a admissão de temporários. Em essência, a Lei 1.093/2009 regulamentou a questão dos temporários deixada em aberto desde a aprovação da Lei 1.010/2007.

A criação de uma série de subcategorias foi essencial para a implementação de um projeto que tinha como finalidade aprofundar o processo de precarização das formas de contratação dos docentes e fragmentação da categoria. Vimos, portanto, a categoria de docentes estaduais em São Paulo ser dividida administrativamente. A Lei 1.093/2009 não determinou literalmente a denominação por letras, mas possibilitou essa medida, uma vez que estipulou a diferenciação dos docentes de acordo com o seu vínculo empregatício. Vejamos no "Quadro 1", a seguir, como ficaram divididos os docentes de acordo com sua forma de contratação e situação funcional após a publicação da Lei 1.093/2009.

A Lei 1.093/2009 significou a coroação do projeto de alteração nas relações de contrato e das condições e organização do trabalho docente, protagonizadas pelo governo estadual. Sem dúvida, foi um marco para os docentes, pois colocou novos paradigmas para a constituição da carreira e para o movimento dos trabalhadores da educação. Não podemos deixar de ponderar que essa Lei arbitra pormenorizadamente a contratação precária com o apoio de outros dispositivos normativos complementares que foram publicados pelo governo com base nela.

A primeira questão é a regulamentação da contratação de trabalhadores por tempo determinado para o atendimento de necessidades temporárias "de excepcional interesse público", prevista na Constituição Estadual no seu Artigo 115, inciso X, e até aquele momento, regulamentada pela Lei 500/1974. Apesar de ser uma Lei criada para regulamentar a contratação de trabalhadores temporários em todo o serviço público estadual, consideramos que seu foco principal recaiu sobre o setor educacional, principalmente na situação dos docentes temporários. Afirmamos isso em razão do

\section{Quadro I - Possibilidades de vínculo contratual de docentes na Rede Estadual de SP}

\begin{tabular}{l}
$A=$ Efetivo (Titular de Cargo) \\
\hline $\mathrm{P}=$ Estável (Constituição Federal de 1988) \\
\hline $\mathrm{F}=$ Docente ACT* - Com aula em (2/6/07) data da LC 1.010/2007 \\
\hline $\mathrm{L}=$ Docente ACT - Aulas após (2/6/07) LC 1.010/2007 e antes de (17/7/09) LC 1.093/2009 \\
\hline $\mathrm{O}=$ Docente ACT - Candidato à admissão, após (17/7/2009) data da LC 1.093/2009 \\
\hline $\mathrm{S}=$ Docente Eventual - Vinculado em (2/6/2007), da LC 1.010/2007 \\
\hline $\mathrm{I}=$ Docente Eventual - Vínculo após (206/07), LC 1.010/2007 e antes de (17/7/09) LC \\
1.093/2009. \\
\hline $\mathrm{V}=$ Docente Eventual - Candidato à admissão após (17/7/2009) data da LC 1.093/2009. \\
\hline $\mathrm{R}=$ Readaptado \\
\hline * Admitido em caráter temporário. \\
Fonte: CGRH/SEE - disponível em http://www.educacao.sp.gov.br/cgrh/consultas/ acesso em 28/1/2017 às 16h38 - \\
Org. Diego Vilanova
\end{tabular}


número expressivo de vezes em que é citada a categoria docente no texto da Lei.

Como no exemplo do primeiro artigo, inciso IV:

Lei 1.093/2009

Artigo $1^{\circ}$.

IV - para suprir a atividade docente da rede de ensino público estadual, que poderá ser feita nas hipóteses previstas no inciso II deste artigo e, ainda, quando: a) o número reduzido de aulas não justificar a criação de cargo correspondente;

b) houver saldo de aulas disponíveis, até o provimento do cargo correspondente;

c) ocorrer impedimento do responsável pela regência de classe ou magistério das aulas (SÃO PAULO, 2009, p. 1).

Ou ainda no artigo 10 e no parágrafo único:

Lei 1.093/2009

Artigo 10 - O contratado nos termos desta lei complementar está sujeito aos mesmos deveres, proibições e responsabilidades previstos na Lei $\mathrm{n}^{\circ}$. 10.261, de 28 de outubro de 1968, aplicando-se aos docentes, subsidiariamente, as disposições da Lei complementar $n^{\circ} .444$, de 27 de dezembro de 1985.

Parágrafo único - No caso de função docente, observado o $\S 1^{\circ}$. do artigo $7^{\circ}$. desta lei complementar e o artigo 11 da Lei complementar $n^{\circ}$. 836 , de 30 de dezembro de 1997 , as contratações a que se refere o "caput" deste artigo estarão automaticamente extintas após 2 (dois) anos letivos subsequentes ao que estiver em curso na data da publicação desta lei complementar (SÃO PAULO, 2009, p. 3).
Além dessas especificações peculiares aos docentes, a Lei conta com todos os artigos das disposições transitórias dedicados exclusivamente aos mestres, são quatro artigos e um parágrafo único, além do termo "docente" ou "docentes" aparecerem 20 vezes no corpo da Lei, o termo "magistério" 1 (uma) vez e "educação" 8 (oito) vezes. Essa recorrência nos indica que a nossa hipótese tem forte fundamento. O ordenamento jurídico estadual não permitiria que se estabelecesse forma de contratação específica aos docentes que não coadunasse com as demais categorias profissionais de servidores públicos estaduais. No entanto, existe uma arquitetura no conjunto das leis que é pensada para a categoria docente deliberadamente.

Segundo dados do $\mathrm{CGRH},{ }^{2}$ combinados com os da Secretaria de Administração e Recursos Humanos do Governo do Estado de São Paulo, em 2008 (ano no qual se apresentou o projeto de lei), dos 100 mil trabalhadores temporários no serviço público estadual, 83 mil eram docentes. Isso nos ajuda a entender a centralidade que a rede estadual de Ensino ganha em uma política de precarização das formas de contratação e das condições de trabalho dos contratados temporariamente. Pois do total de contratados temporariamente, a grande maioria são professores. Também fica clara a intenção do governo de dar respostas aos problemas dos temporários

2 Dados fornecidos por e-mail pelo SIC - Serviço de informação ao cidadão após solicitação enviada, segundo o SIC a origem dos dados é a Unidade Central de Recursos Humanos do Estado de São Paulo. Solicitação registrada pelo protocolo $n^{\circ} .3970717795$ e respondida da seguinte forma: "Em atendimento ao questionado efetuamos consulta ao Cadastro de Servidores do Departamento de Despesa de Pessoal do Estado - DDPE, da Secretaria da Fazenda, onde constam dados da Administração Direta (Secretarias) e localizamos os quantitativos que seguem [...]" 
na Educação com a aprovação dessa norma, quando analisamos o discurso oficial do governo por ocasião do encaminhamento do Projeto de Lei à Assembleia Legislativa do Estado de São Paulo. Na mensagem de número 36, de 5 de maio de 2009, o governador diz que os novos regramentos para a contratação temporária visam atender "[...] em particular nas áreas da Educação e da Saúde, justamente onde tem ocorrido em maior número, devido às características dos respectivos quadros de pessoal" (SÃO PAULO, 2017).

A extinção das contratações por meio da Lei 500/1974, a partir da publicação da Lei 1.093/2009 em diante e a extinção dos contratados nessa condição após a aprovação da Lei 1.010/2007, é outra marca determinante e explicitadora do que dizemos:

\begin{abstract}
Lei 1.093/2009
Artigo 24 - Fica vedada, a partir da publicação desta lei complementar, a admissão de pessoal com fundamento na Lei $n^{\circ}$. 500, de 13 de novembro de 1974.

Artigo 25 - As contratações de pessoal após o advento da Lei complementar $\mathrm{n}^{\circ}$. 1.010 , de $1^{\circ}$. de junho de 2007, sob o regime jurídico da Lei $n^{\circ} .500$, de 13 de novembro de 1974 , estarão automaticamente extintas (SÃO PAULO, 2009, p. 3).
\end{abstract}

O artigo 25 é o que extingue os docentes temporários da categoria “L", portanto, findado o período letivo, esses docentes só poderiam ser recontratados na condição de categoria "O", o último com os seus direitos completamente reduzidos por essa nova forma de contratação. A Lei 1.093/2009 cria todo um novo regramento para os temporários desde sua forma de contratação até os direitos mais gerais. Nela está assegurado apenas o $13^{\circ}$. salário proporcional aos meses trabaIhados e a remuneração das férias, desde que completados 12 meses de trabalho:
Lei 1.093/2009

Artigo 12 - Fica assegurado ao contratado nos termos desta lei complementar: I - o décimo terceiro salário, na proporção de 1/12 (um doze avos) por mês trabalhado ou fração superior a 15 (quinze) dias;

II - o pagamento das férias, decorridos 12 (doze) meses de efetivo exercício da função (SÃO PAULO, 2009, p. 2).

Por conta da suspensão do contrato de trabalho que eventualmente ocorre até que o docente da categoria "O" consiga atribuir classes e/ou aulas de um ano letivo ao outro, seu cômputo de meses trabalhados não atinge os 12 meses que a Lei prevê para que receba as férias. Sendo assim, não são raros os casos em que os docentes da categoria "O" só receberam férias no segundo ano letivo de trabalho. Ou seja, trabalhando de fevereiro a dezembro, o docente soma apenas 10 meses de trabalho, precisa de uma parte do ano letivo seguinte para que se completem os 12 meses necessários para perceber os vencimentos referentes às férias.

Os demais direitos, ou na verdade a retirada deles, foram regulamentados por meio da publicação do Decreto 54.682/2009, que trata da regulamentação da aplicação da Lei Complementar 1.093/2009. A partir de agora analisaremos a referida Lei com as demais normas que tratam da sua aplicação, dessa forma acreditamos que fique mais evidente as questões que almejamos destacar, ganhando, inclusive, mais sentido.

A publicação do Decreto consagrou a diminuição de direitos aos docentes da categoria “O”. Direitos históricos que são assegurados aos efetivos são reduzidos ou extintos quando se refere aos docentes da categoria “O”, como: A Licença gala de 8 (oito) dias é reduzida para 2 (dois) dias; Licença nojo de 8 (oito) (para parentes próximos) para 2 (dois) dias. Extinção da Licença nojo para sogro, sogra, padrasto, madrasta e outros parentes. Só 
prevê indenização no caso de dispensa por interesse da administração.

\section{Lei $1.093 / 2009$}

Artigo $8^{\circ}$.

$\S 1^{\circ}$. - A extinção do contrato com fundamento nos incisos I a VII deste artigo far-se-á sem direito a indenização.

$\S 2^{\circ}$. - A extinção do contrato com fundamento no inciso VIII deste artigo implicará o pagamento ao contratado de indenização correspondente a 1 (uma) vez o valor da remuneração mensal fixada no contrato, ou, quando for o caso, da média mensal da remuneração fixada no contrato, até o advento da extinção (SÃO PAULO, 2009, p. 1).

A Licença maternidade assegurada as docentes em Regime Próprio de Previdência dos Servidores Públicos Estaduais de São Paulo (RPPS) de 6 (seis) meses é reduzida a 4 (quatro) meses por conta das docentes da categoria "O" estarem vinculadas ao Regime Geral de Previdência Social (RGPS/INSS):

Lei 1.093/2009

Artigo 20 - O contratado na forma do disposto nesta lei complementar ficará vinculado ao Regime Geral de Previdência Social, nos termos da legislação federal (SÃO PAULO, 2009, p. 2).

Resolução SE - 68

Art. 14 - O docente contratado ficará vinculado ao Regime Geral de Previdência Social - RG PS, nos termos da legislação federal, devendo incidir sobre sua remuneração mensal o desconto relativo ao recolhimento previdenciário (SÃO PAULO, 2009, p. 33-34).

As faltas abonadas caem de 1 (uma) por mês no máximo 6 (seis) ao ano para 1 (uma) por mês com o máximo de 2 (duas) enquanto durar o contrato. Isso significa que se o contrato é renovado, são duas faltas abonadas em um período de 2 (dois) anos. As faltas justificadas, que no caso dos docentes efetivos são de até 24 (doze justificadas pela direção da escola e mais 12 pelo dirigente de ensino), caem para apenas 3 (três) para os professores da categoria "O". Enquanto as faltas injustificadas para caracterização de abandono de cargo são: 30 faltas consecutivas ou 45 interpoladas para os titulares de cargo efetivos (segundo o estatuto do servidor público estadual) e 15 consecutivas ou 30 interpoladas para os docentes da categoria " $F$ " (conforme Lei 500/1974), para os da categoria “O” é apenas 1 (uma). Isso foi possível pela publicação da Resolução SE - 68, de 1-10-2009 (D.O.E. 02/10/2009) pois na Lei 1.093/2009 a questão das faltas injustificadas não ficou claramente estabelecida, a referida resolução, entre outras coisas, determina:

$$
\begin{aligned}
& \text { Resolução SE - 68/2009 } \\
& \text { Art. } 9^{\circ} \text {. } \\
& \S 4^{\circ} \text {. - Somente poderá ocorrer } 1 \\
& \text { (uma) falta injustificada durante a } \\
& \text { vigência da contratação, sendo que } \\
& \text { a segunda ocorrência será consi- } \\
& \text { derada como de descumprimento } \\
& \text { de obrigação contratual por parte } \\
& \text { do docente, implicando a possibili- } \\
& \text { dade de extinção do contrato, nos } \\
& \text { termos do artigo } 8^{\circ} \text {. da Lei Comple- } \\
& \text { mentar } n^{\circ} \text {. 1.093/2009 (SÃO PAULO, } \\
& 2009, \text { p. } 33-34 \text { ). }
\end{aligned}
$$

Enfim, são inúmeras as diferenças no que tange aos direitos trabalhistas entre os professores efetivos e temporários da categoria "F" e os da categoria "O". Criando assim a celeuma de condições sociais de trabalho e contratos de trabalho distintos para cada uma delas. Ou seja, mesma função, mesmo trabalho e direitos e condições de trabaIho distintas. Medidas essas asseguradas por uma diferenciação feita a partir da forma de contratação, como podemos apurar observando o "Quadro 2" logo a seguir. 
Quadro 2 - Quadro comparativo entre os direitos e condições de trabalho dos docentes estaduais de São Paulo por forma de vínculo/contrato

\begin{tabular}{|c|c|c|c|}
\hline $\begin{array}{l}\text { Direitos e condições } \\
\text { de trabalho }\end{array}$ & \begin{tabular}{|l} 
Categoria A - \\
Efetivo de cargo \\
(Lei 10.261/68) \\
8 dias para parentes \\
próximos e 2 para \\
outros graus de \\
parentesco
\end{tabular} & $\begin{array}{l}\text { Categoria F - } \\
\text { Contratado pela } \\
\text { Lei } 500 / 74 \text { e estável } \\
\text { pela Lei } 1.010 / 07 \\
8 \text { dias para parentes } \\
\text { próximos e } 2 \text { para } \\
\text { outros graus de } \\
\text { parentesco }\end{array}$ & $\begin{array}{l}\text { Categoria O - } \\
\text { Contratado pela Lei } \\
1.093 / 09 \\
2 \text { dias para parentes } \\
\text { próximos }\end{array}$ \\
\hline Licença Gala & 8 dias & 8 dias & 2 dias \\
\hline Faltas Médicas & $\begin{array}{l}6 \text { ao ano máximo } 1 \\
\text { por mês }\end{array}$ & $\begin{array}{l}6 \text { ao ano máximo } 1 \\
\text { por mês }\end{array}$ & $\begin{array}{l}6 \text { ao ano máximo } 1 \text { por } \\
\text { mês }\end{array}$ \\
\hline Licença Maternidade & 180 dias & 180 dias & 120 dias \\
\hline Faltas Abonadas & $\begin{array}{l}6 \text { ao ano máximo } 1 \\
\text { por mês }\end{array}$ & $\begin{array}{l}6 \text { ao ano máximo } 1 \\
\text { por mês }\end{array}$ & $\begin{array}{l}2 \text { por ano máximo } 1 \text { por } \\
\text { mês }\end{array}$ \\
\hline Faltas Justificadas* & $\begin{array}{l}24 \text { - (12 pela direção } \\
\text { da U.E e } 12 \text { pela } \\
\text { DRE) }\end{array}$ & $\begin{array}{l}24 \text { - (12 pela direção } \\
\text { da U.E e } 12 \text { pela } \\
\text { DRE) }\end{array}$ & 3- pela direção da U.E \\
\hline $\begin{array}{l}\text { Faltas Injustificadas| } \\
\text { abandono de cargo } \\
\text { ou ruptura de } \\
\text { contrato* }\end{array}$ & $\begin{array}{l}45 \text { interpoladas ou } \\
30 \text { consecutivas }\end{array}$ & $\begin{array}{l}30 \text { interpoladas ou } \\
15 \text { consecutivas }\end{array}$ & 1 \\
\hline $\begin{array}{l}\text { Jornada de Trabalho } \\
\text { garantida }\end{array}$ & $\begin{array}{l}\text { A de opção (12 h } \\
\text { somente ingresso, } \\
24 \text { h, } 30 \text { h e } 40 \mathrm{~h} \text { ) }\end{array}$ & somente $^{12 \mathrm{~h}}$ & Nenhuma \\
\hline $13^{\circ}$. Salário & $\begin{array}{l}\text { Proporcional aos } \\
\text { meses trabalhados }\end{array}$ & $\begin{array}{l}\text { Proporcional aos } \\
\text { meses trabalhados }\end{array}$ & $\begin{array}{l}\text { Proporcional aos meses } \\
\text { trabalhados }\end{array}$ \\
\hline Férias remuneradas & \begin{tabular}{|l} 
Integral com \\
pagamento de $1 / 3$
\end{tabular} & $\begin{array}{l}\text { Integral com } \\
\text { pagamento de } 1 / 3\end{array}$ & $\begin{array}{l}\text { Somente quando } \\
\text { completados } 12 \text { meses }\end{array}$ \\
\hline Assistência Médica & IAMSPE ** & IAMSPE ** & Não tem \\
\hline Previdência & SPPREV|RPPS & SPPREVIRPPS & INSS/RGPS \\
\hline $\begin{array}{l}\text { Estabilidade no } \\
\text { Emprego }\end{array}$ & Sim & $\begin{array}{l}\text { Sim/parcialmente } \\
\text { com jornada } \\
\text { reduzida e processo } \\
\text { seletivo simplificado }\end{array}$ & $\begin{array}{l}\text { Não/cumprimento } \\
\text { de duzentena entre } \\
\text { um contrato e outro } \\
\text { e processo seletivo } \\
\text { simplificado }\end{array}$ \\
\hline
\end{tabular}

Fonte: Legislação Estadual de São Paulo (Leis 10.261/1968, 444/1985, 836/1997, 1010/2007, 1041/2008, 1093/2009, e 1.094/2009; Decretos 51.654/2007, 54.682/2009 e 55.078/2009; Resoluções SE) 67/2009, 68/2009 e SE 87/2009.)

Elaboração: Diego Vilanova

* Com prejuízo do salário

** Instituto de Assistência Médica do Servidor Público Estadual 
Ao mesmo tempo em que assistimos um processo de diferenciação entre os docentes, concernente aos direitos segundo o regime de contratação, no aspecto referente aos deveres, proibições e responsabilidades, verificamos a equiparação:

\section{Lei 1.093/2009 \\ Artigo 10 - O contratado nos ter- mos desta lei complementar está sujeito aos mesmos deveres, proibi- ções e responsabilidades previstos na Lei $n^{\circ}$. 10.261, de 28 de outubro de 1968, aplicando-se aos docentes, subsidiariamente, as disposições da Lei complementar $n^{\circ} .444$, de 27 de dezembro de 1985 (SÃO PAULO, 2009, p. 1). \\ Resolução SE - 68, de 1-10-2009 (D.O.E. 02/10/2009) \\ Art. $8^{\circ}$. - Durante o período da con- tratação, o docente estará sujeito aos mesmos deveres, proibições e responsabilidades previstos na Lei $n^{\circ}$. 10.261/68, bem como, sub- sidiariamente, às disposições da Lei Complementar n ${ }^{\circ}$. 444/85 (SÃO PAULO, 2009, p. 33-34).}

A evidência do movimento de retirada de direitos pode ser constatada, também, no que diz respeito aos professores da Categoria "O" quando analisamos seu contrato de trabalho e o vínculo previdenciário. Os docentes incluídos nessa categoria são contratados por tempo determinado por regramento próprio do governo do Estado de São Paulo, são vinculados ao INSS/RGPS, mas não possuem assegurados os direitos previstos na Consolidação das Leis do Trabalho (CLT), ou seja, não têm acesso ao Seguro Desemprego e Fundo de Garantia por Tempo de Serviço (FGTS). A vinculação ao INSS é meramente previdenciária. Percebam que ao desobrigar-se de manter sob o mesmo regime que os demais servidores, o governo poderia contratá-los como "celetistas" e assim assegurar aos contratados precários todos os direitos e a carteira de trabalho assinada. No entanto, não é isso o que ocorre.

Outra dimensão a ser considerada e que contribui com o cenário de configuração da precariedade do trabalho é a da instabilidade no emprego e da flexibilização das condições sociais de trabalho. Questões essas que trazem ao trabalhador insegurança quanto ao seu destino, trata-se de uma insegurança em relação ao futuro das condições gerais de vida, mas, também referente ao local de trabalho, quantidade de aulas (jornada) etc. Falamos, pois, do novo trabalhador flexível e polivalente na sua versão para o serviço público. Como não poderia deixar de ser, a lei 1.093/2009 atentou-se a estas questões:

\section{Lei $1.093 / 2009$}

Artigo $6^{\circ}$. - É vedada, sob pena de nulidade, a contratação da mesma pessoa, com fundamento nesta lei complementar, ainda que para atividades diferentes, antes de decorridos 200 (duzentos) dias do término do contrato.

Artigo $7^{\circ}$. - A contratação será efetuada pelo tempo estritamente necessário para atender às hipóteses previstas nesta lei complementar, observada a existência de recursos financeiros e o prazo máximo de até 12 (doze) meses, ressalvada, quanto à vigência, a contratação para função docente, que fica limitada ao ano letivo fixado no calendário escolar.

$\S 1^{\circ}$. - Os direitos e obrigações decorrentes da contratação para função docente ficarão suspensos sempre que ao contratado não forem atribuídas aulas, sendo-lhe facultado, no período de vigência do contrato, aceitar ou não as que forem oferecidas.

$\S 2^{\circ}$. - Findo o prazo de vigência, o contrato estará automaticamente 
extinto (SÃO PAULO, 2009, p. 1).

Assim como também vimos essa questão ser regulamentada e arbitrada na

\section{Resolução SE - 68}

Art. $3^{\circ}$. - O prazo de vigência da contratação de docentes limita-se ao ano letivo fixado no calendário escolar.

Art. $4^{\circ}$. - Na vigência de uma contratação, os direitos e deveres ficarão suspensos durante o(s) período(s) em que o docente contratado tenha interrupção de exercício, em decorrência de perda, por qualquer motivo, da classe ou das aulas anteriormente atribuídas.

$\S 2^{\circ}$. - No período de interrupção de exercício não haverá remuneração ao docente nem concessão de benefício, vantagem, licença ou afastamento de qualquer espécie.

Art. $7^{\circ}$. - Na vigência do contrato, o docente não poderá se afastar do exercício da função, objeto da contratação, para exercer outras atribuições e/ou atividades diversas, a título de designação, afastamento ou nomeação em comissão.

$\S 1^{\circ}$. - O docente contratado poderá ter exercício em mais de uma unidade escolar e, conforme o caso, em mais de uma Diretoria de Ensino, de acordo com as aulas que Ihe sejam atribuídas, sendo que sua carga horária poderá sofrer alterações, para maior ou menor, no decorrer do ano letivo (SÃO PAULO, 2009, p. 33-34).

Significa, pois, que para o caso dos docentes, a própria vigência do contrato está condicionada ao período letivo, que sabemos é de cerca de 10 meses ao ano, permanecendo suspenso no interstício entre um ano letivo e outro. A suspensão do contrato condiciona o docente precário ao não recebimento de salário e de qualquer benefício que o contrato lhe assegure conforme reza o $\S 2^{\circ}$. Ou seja, o contrato fica suspenso por dois meses (período de férias escolares), encontrando seu final após o retorno do ano letivo e decorridos mais dois meses, por exemplo, somando no total 14 meses de contrato dos quais apenas 12 puderam ser realizados com trabalho e remunerado. Essa hipótese considera o melhor cenário de tempo de duração em meses de vigor do contrato, visto que, como discutiremos mais adiante, tudo isso está condicionado à atribuição de aulas ou não ao docente precário. É como se o trabalhador ficasse em stand by até conseguir aulas, sem nada receber.

O dispositivo de suspensão do contrato permite que o docente fique submetido à existência ou não de aulas a serem atribuídas, e mesmo depois de atribuídas possibilita que sejam retiradas sem que isso interfira no contrato, ou seja, ele é suspenso novamente. Não seria o caso de uma interrupção do contrato por interesse da administração e sendo assim passível de indenização? No entanto, não se considera interrupção, e sim suspensão, logo após ele pode ser retomado assim que o docente atribuir mais aulas, ou seja, o contrato é reativado.

A possibilidade de o docente iniciar outro ano letivo antes de computados os 12 meses máximos de vigência do contrato viabilizados pelo dispositivo de suspensão do contrato esbarraria na situação de ocorrer de o docente ser demitido no meio do ano letivo, para que isso não acontecesse o governo fixou, no artigo $7^{\circ}$. da lei, a possibilidade de extensão do tempo de contrato até o fim do ano letivo. Essa condição prevista na lei ficou restrita aos docentes, lembrando que a Lei 1.093/2009 arbitra as contratações temporárias em todo o serviço público estadual. Os dispositivos que o referido artigo versa é o que permite que o contrato tenha um número de meses superior, em muito, aos doze meses originalmente estabelecidos.

A "duzentena", como ficou conhecido o período de 200 dias aos quais o docente contratado nos moldes da Lei 1.093/2009 
tem que aguardar antes de firmar novo contrato (artigo $6^{\circ}$.), também é um elemento de instabilidade no emprego e submete esses profissionais a uma situação de subemprego permanente. Significa que entre um contrato e outro o docente tem de cumprir um interstício de 200 dias, não só não pode firmar novo contrato antes de findar esse período, no magistério como também a Lei proíbe que seja contratado temporariamente para qualquer função do serviço público estadual de São Paulo. É a certeza de um ciclo de subemprego e desemprego.

No entanto, no discurso oficial via-se a seguinte perspectiva:

MENSAGEM 36, DE 5 DE MAIO DE 2009 do PLC 19/2009

Resultante de estudos desenvolvidos por Grupo de Trabalho instituído em ato do Secretário-Chefe da Casa Civil (Resolução CC-37, de 30 de agosto de 2007), examinados no âmbito do Comitê de Qualida- de da Gestão Pública e das Secretarias de Gestão Pública, da Educação e da Saúde, a propositura se insere no conjunto de medidas destinadas a atualizar a legislação pertinente à contratação temporária, bem como reduzir os casos de sua admissibilidade [...] (SÃO PAULO, 2017).

$\mathrm{O}$ argumento do governo de que eram medidas para diminuir o montante de contratos temporários não se comprovou. Ao contrário, vimos os casos de contratos temporários sofrerem um aumento conforme podemos verificar observando o Gráfico 1. No ano de 2010, primeiro ano de integral vigência da Lei 1.093/2009, o número de docentes não efetivos aumentou em 10.797, saltando para 101.375 , se utilizarmos como referência o mês de junho.

Não só aumentaram os temporários em números absolutos, como também o percentual de docentes não efetivos aumentou ano a ano no período que se seguiu à publicação

Gráfico 1 - Total de professores, efetivo e não efetivos na rede estadual, por quantidade e ano - (2007-2010)

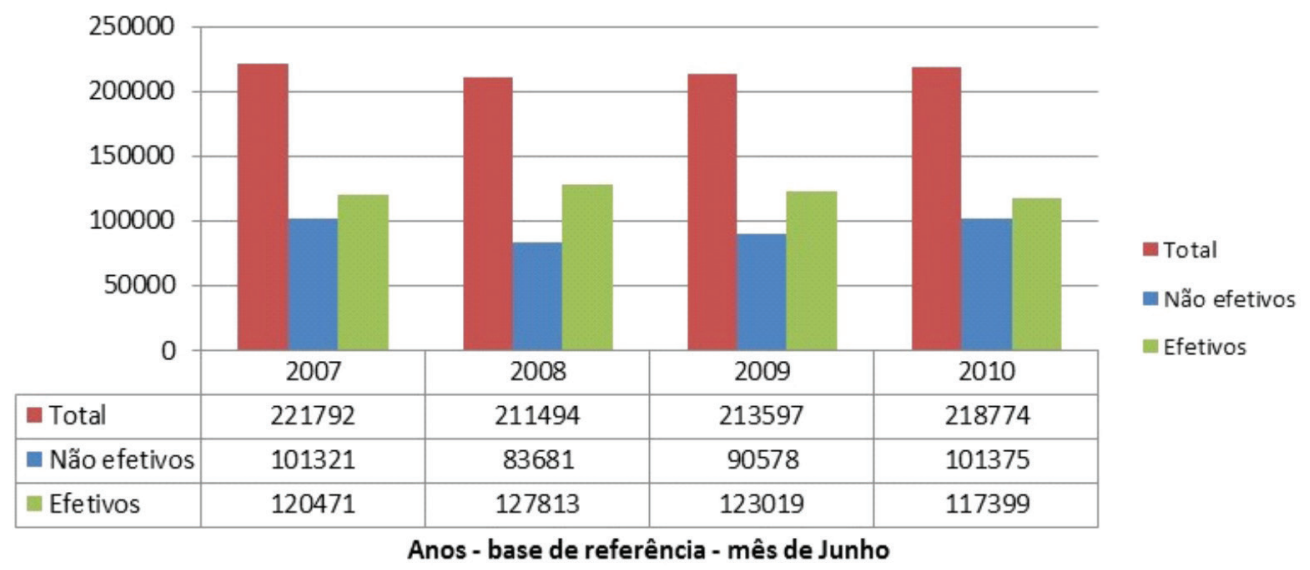

Fonte: CGRH/SEE - disponível em http://www.educacao.sp.gov.br/cgrh/consultas/ acesso em 27/01/2017 às 21 h47 Organização: DIEESE/sub-seção APEOESP - Obtidos por meio de solicitação.

Elaboração: Diego Vilanova 
da norma. Em 2009, a rede estadual contava com 41,1\% dos docentes não efetivos, em 2010 esse número saltou para $45,9 \%$ e continuou crescendo: 2011 - 46,8\%; 2012 - 47,9\%. ${ }^{3}$

A análise do período de 2000 a 2014 demonstra que esse percentual sempre esteve acima dos $40 \%$, e não diminuiu com a adoção dessas medidas. Ou seja, os números de contratados temporariamente só aumentou.

Se observarmos os temporários por vínculo funcional, divididos pelas subcategorias “F”, “L” e "O", vemos que também subiu o número de professores da Categoria "O" consideravelmente, além de aumentar os temporários de um modo geral, os mais precarizados (única forma de contratação temporária possível, após a aprovação da Lei 1.093/2009) aumentaram mais, conforme demonstrado no Gráfico 2.

Os contratados temporários da categoria “O”, mais precarizados, saltaram de 15.400, em 2010, para 61.900, em 2013, um aumento de $400 \%$. Assim se evidencia ainda mais que a precarização dos docentes estaduais foi uma política de governo. Esses dados também esvaziam o discurso oficial de precarização da contratação temporária para a sua diminuição.

A flexibilidade dos dispositivos contratuais, que ocorre com a suspensão do contrato nos períodos não letivos e quando o docente não consegue atribuir aulas, está diretamente associada ao fenômeno que denominamos nesta pesquisa de "efeito sanfona". O Estado contrata o docente para o início do ano letivo e dispensa ao final dele com a suspensão contratual. No início do ano letivo seguinte, recontrata esse mesmo docente, compondo um cenário de aumento crescente de contratos temporários ao longo do ano e de sua diminuição no início do ano.

Esse fenômeno é explicado em parte também por conta do crescente número de afastamentos por motivos médicos e de exonerações que aumentam no segundo semestre devido ao estafe gerado pelas próprias condições de trabalho.

\section{Gráfico 2 - Evolução do número de professores, por vínculo funcional na Rede Estadual de São Paulo}

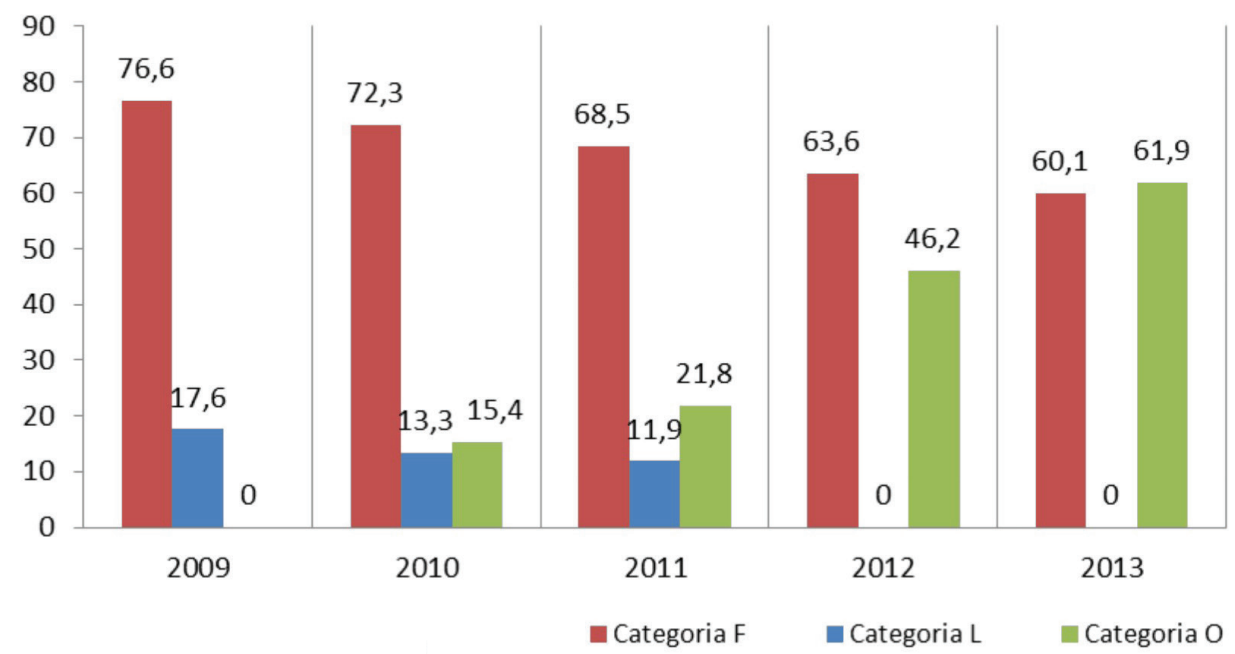

Fonte: CGRH/SEE - disponível em http://www.educacao.sp.gov.br/cgrh/consultas/ acesso em 27/01/2017 às 21h53 Organização: DIEESE/sub-seção APEOESP - Obtidos por meio de solicitação. Elaboração: Diego Vilanova

3 Fonte: SEE/CGRH Fonte: CGRH/SEE - disponível em http://www.educacao.sp.gov.br/cgrh/consultas/ 
Tabela 1 - Total de professores efetivos e não efetivos por ano e por mês de referência (2007-2014)

\begin{tabular}{|c|c|c|c|c|c|c|c|c|}
\hline \multirow{2}{*}{ Ano/Mês } & \multicolumn{2}{|c|}{2007} & \multicolumn{2}{c|}{2008} & \multicolumn{2}{c|}{2009} & \multicolumn{2}{c|}{2010} \\
\cline { 2 - 9 } & Efetivos & Năo efetivos & Efetivos & Nầo efetivos & Efetivos & Nä́o efetivos & Efetivos & Não efetivos \\
\hline Fevereiro & 122342 & 67456 & 130501 & 71465 & 125865 & 75023 & 120261 & 90321 \\
\hline Junho & 120471 & 101321 & 127813 & 83681 & 123019 & 90578 & 117399 & 101375 \\
\hline Novembro & 118434 & 106785 & 125352 & 95334 & 120984 & 97342 & 115987 & 103844 \\
\hline
\end{tabular}

\begin{tabular}{|c|c|c|c|c|c|c|c|}
\hline \multicolumn{2}{|c|}{2011} & \multicolumn{2}{c|}{2012} & \multicolumn{2}{c|}{2013} & \multicolumn{2}{c|}{2014} \\
\hline Efetivos & Nà̃o efetivos & Efetivos & Nã̃o efetivos & Efetivos & Vão efetivo: & Efetivos & Não efetivo: \\
\hline 119399 & 91194 & 123755 & 90837 & 120886 & 85525 & 114967 & 101975 \\
\hline 118827 & 101407 & 120888 & 107236 & 118870 & 114444 & 124028 & 117329 \\
\hline 116927 & 106301 & 117623 & 115174 & 116122 & 124718 & 138708 & 112028 \\
\hline
\end{tabular}

Fonte: CGRH/SEE - disponível em http://www.educacao.sp.gov.br/cgrh/consultas/acesso em 27/01/2017 às 21h47 Organização: DIEESE/sub-seção APEOESP - Obtidos por meio de solicitação.

Elaboração: Diego Vilanova

Na Tabela 1, organizamos os dados de três meses por ano de 2007 a 2014, escolhemos os meses de fevereiro (por se tratar do início do ano letivo), junho (meio do ano) e novembro (final do ano letivo). Comumente o ano letivo se encerra na segunda quinzena de dezembro e começa na primeira de fevereiro. Sendo assim, acreditamos que com esse recorte seja possível a apuração do fenômeno descrito como "efeito sanfona". Cabe reiterar que os números expressos na tabela referem-se aos docentes que estão com contrato estabelecido. A título de esclarecimento, vale ressaltar que nas contas do governo, no entanto, os docentes com o contrato suspenso continuam sendo computados na condição de contratado. Dessa forma, somente os que o contrato efetivamente deixou de existir ao final do ano letivo e passaram a cumprir a "duzentena" é que deixam de ser temporários para o governo. Resumidamente, significa que os computados como contratados temporariamente na categoria "O" não estão efetivamente com os seus contratos vigorando no período não letivo, estando, portanto, na nossa opinião demitidos. Sendo recontratados no período letivo posterior.

Mesmo assim, notamos o aumento sazonal das contratações temporárias. Considerando isso, podemos dizer que todos os não efetivos da categoria “O”, regidos pelo contrato estabelecido pela Lei 1.093/2009, são demitidos e readmitidos a cada ano letivo ou quando atribuem e perdem aulas. Seguindo esse raciocínio, esses dados se multiplicam consideravelmente.

Para nós, a suspensão do contrato é análoga à demissão temporária, pois não assegura nada ao contratado durante o período de suspensão. Estamos falando de cerca de 80 mil docentes só no ano de 2010 (Fonte: CGRH/SEE - disponível em http://www.educacao.sp.gov.br/cgrh/consultas), o que sem dúvidas significa que só nesse ano cerca de 160 mil salários deixaram de ser pagos (dois meses por contratado temporariamente), fora as demais despesas decorrentes da manutenção dos direitos que os contratados da categoria "O" não gozam. 


\section{CONSIDERAÇÕES FINAIS}

Com base nos aspectos aqui analisados, consideramos que as políticas empreendidas no governo José Serra (2007-2010) para a Educação tiveram como foco principal promover mudanças no regime de contratação docente que contribuíram para o aprofundamento do processo de precarização do trabalho. Aqui, neste trabalho, analisamos os efeitos da Lei 1.093/2009 no sentido das clivagens na categoria. Apresentamos os primeiros resultados de um dos aspectos que estão sendo analisados na Dissertação de Mestrado que se encontra em fase de redação.

Além das questões já descritas, a Lei 1.093/2009 abre um leque de possibilidades relacionadas aos seguintes pontos: a) local de trabalho pois, na maior parte dos casos, os docentes precisam lecionar em mais de uma escola e mudar várias vezes de escola ao longo do ano; b) jornada de trabalho uma vez que o número de aulas varia, aumenta e diminui ao longo do ano e com ela o salário e; c) tempo de duração do contrato que por ser extremamente volátil não oferece segurança alguma ao trabalhador, mesmo depois de estabelecida a contratação.
A condição precária se expressa ainda na impossibilidade de evolução funcional, na exclusão do plano de carreira, nos cargos e salários, aspectos que, em conjunto, significam a extensão da falta de perspectivas e valorização do trabalho dos docentes submetidos a tal regime de contratação temporária. Isso ocorre porque a contratação sempre é feita com base na faixa de vencimentos iniciais, desprezando para fins do pagamento o tempo de trabalho, a experiência e a titulação, entre outros aspectos.

Um plano de carreira, cargos e salários ${ }^{4}$ e a possibilidade de evolução funcional é uma conquista histórica da categoria docente e tem sido recorrentemente fruto de amplos debates e mobilizações desse segmento, sempre na perspectiva de ampliá-lo, aprimorá-lo e estendê-lo aos contratados pela categoria "O”. Esses últimos, diferentemente dos da categoria "F", não são enquadrados nas prerrogativas do plano de carreira do magistério.

Enfim, estamos convencidos que as alterações no arcabouço legal efetuadas pelo governo de José Serra em São Paulo, entre os anos de 2007 e 2010, especificamente a Lei e normativas analisadas neste trabalho, aprofundam e consolidam uma perspectiva de contratação precária e de precarização das relações sociais de trabalho docente.

4 LEI COMPLEMENTAR No. 836, DE 30 DE DEZEMBRO DE 1997, Institui Plano de Carreira, vencimentos e salários para os integrantes do Quadro do Magistério da Secretaria da Educação. 


\section{REFERÊNCIAS}

ABONIZIO, G. A precarização do trabalho docente: Apontamentos a partir de uma análise bibliográfica. Ensino de Sociologia em debate, Londrina, v. 1, n. 1, jan./jun., 2012.

ALVES, Giovanni. Dimensões da Reestruturação Produtiva - Ensaios de sociologia do trabalho, Bauru, Editora Praxis, 2007.

CALLEGARI, C. Org. O FUNDEB e o financiamento da Educação Pública no Estado de São Paulo, São Paulo: Aquariana: IBSA: APEOESP, 2009, 448p., 4 a . edição.

CARVALHO, C. RUSSO, M. Reforma e Políticas de Educação do Governo do Estado de São Paulo (2007-2011). Série-Estudos - Periódico do Programa de Pós-Graduação em Educação da UCDB, Campo Grande, n. 34, jul./dez., 2012.

CASTEL, ROBERT. Metamorfoses da questão social. Uma crônica do salário, Petrópolis: Vozes, 1998.

COSTA, A. FERNANDES, E. N., SOUZA, G. A proletarização do professor: Neoliberalismo na Educação, São Paulo: Editora Instituto José Luis e Rosa Sundermann, 2009, 144p., 2 ${ }^{a}$. edição.

FERNANDES, Maria José da Silva. As recentes reformas educacionais paulistas na visão dos professores. Educ. rev., Belo Horizonte, v. 26, n. 3, dez., 2010.

HELOANI, José Roberto. Gestão e Organização no Capitalismo Globalizado: História da manipulação psicológica no Mundo do Trabalho, São Paulo: Atlas, 2003., 240p.

HYPOLITO, Álvaro Moreira. Políticas curriculares, Estado e regulação. Educ. Soc., Campinas, v. 31, n. 113, dez., 2010.

LAPO, Flavinês Rebolo; BUENO, Belmira Oliveira. O Abandono do Magistério: Vínculos e Rupturas com Trabalho Docente. Psicol. USP, São Paulo, v. 13, n. 2, 2002.

LELIS, Isabel. $O$ trabalho docente na escola de massa: desafios e perspectivas. Sociologias, Porto Alegre, v. 14, n. 29, abr., 2012.

OLIVEIRA, Dalila Andrade. A reestruturação do trabalho docente: precarização e flexibilização. Educ. Soc., Campinas, v. 25, n. 89, dez., 2004.

POCHMANN, M. O emprego na globalização: a nova divisão internacional do trabalho e os caminhos que o Brasil escolheu, São Paulo: Boitempo, 2002.

SALERNO, M. S. Essência e aparência na organização da produção e do trabalho das fábricas 'reestruturadas'. Produção, v. 5, n. 2, p. 191-202, nov., 1995.

SANFELICE, J. L. A política educacional do Estado de São Paulo: Apontamentos. Nuances: estudos sobre Educação. Ano XVII, v. 17, n. 18, p. 146-159, jan./dez., 2010.

SÃO PAULO (Estado) Secretaria da Educação. Legislação de Ensino Fundamental e Médio. Estadual. Unificação de Dispositivos Legais e Normativos relativos ao Ensino Fundamental e médio, coordenação de Leslie Maria José da Silva Rama, São Paulo, SECRETARIA DA EDUCAÇÃO, 2010.

SÃO PAULO (Estado). Lei Complementar n. 1.093, de 16 de junho de 2009. Dispõe sobre a contratação por tempo determinado de que trata o inciso X do artigo 115 da Constituição Estadual. Diário Oficial [do Estado de São Paulo], São Paulo, SP, v. 119, n. 131, 17 jun., 2009. Seção 1 - Poder Executivo, p. 1-3. 
. Projeto de Lei Complementar 19 (PLC 19), de 7 de maio de 2009. Dispõe sobre a contratação por tempo determinado de que trata o inciso X do artigo 115 da Constituição Estadual. Parecer $n^{\circ}$. 1.115, de 2009, da Comissão de Redação. ALESP - Assembleia Legislativa do Estado de São Paulo, São Paulo, SP. Disponível em: <http://www.al.sp.gov.br/propositura/?id=865501> Acesso em: 11 jan., 2017.

. Projeto de Lei Complementar 20 (PLC 20), de 7 de maio de 2009. Institui a Jornada Integral de Trabalho Docente e a Jornada Reduzida de Trabalho Docente para os integrantes do Quadro do Magistério da Secretaria da Educação e cria os cargos de docente que especifica. Parecer $n^{\circ}$. 1.116, de 2009, da Comissão de Redação. ALESP - Assembleia Legislativa do Estado de São Paulo, São Paulo, SP. Disponível em: <http://www.al.sp.gov.br/propositura/?id=865502> Acesso em: 11 jan., 2017.

. Resolução SE - 68, de $1^{\circ}$. de outubro de 2009. Dispõe sobre a contratação de docentes por tempo determinado, de que trata a Lei Complementar $n^{\circ} .1 .093$, de 16 de julho de 2009, e dá providências correlatas o Secretário da Educação, tendo em vista as disposições da Lei Complementar $n^{\circ} .1 .093$, de 16 de julho de 2009, bem como do Decreto $n^{\circ} .54 .682$, de 13 de agosto de 2009, que a regulamenta, e considerando a necessidade de estabelecer normas e critérios relativos à contratação temporária de docentes, para reger classes e ministrar aulas nas escolas da rede pública estadual. Diário Oficial [do Estado de São Paulo], São Paulo, SP, v. 119, n. 185, 2 out., 2009. Seção 1 - Poder Executivo, p. 33-34.

SILVA, Juan Carlos. A política educacional do governo José Serra (2007-2010): uma análise da atuação da Apeoesp. IV Seminário da Rede Aste, Niterói, Universidade Federal Fluminense, 1820 de abril de 2013.

SOUZA, Aparecida Neri de; LEITE, Marcia de Paula. Condições de trabalho e suas repercussões na saúde dos professores da educação básica no Brasil. Educ. Soc., Campinas, v. 32, n. 117, dez., 2011.

\section{DADOS DOS AUTORES}

\section{EVALDO PIOLLI}

Doutor em Educação pela Universidade Estadual de Campinas. Professor do programa de Pós-graduação em Educação da UNICAMP e pesquisador do Laboratório de Gestão Educacional. Campinas/SP - Brasil.epiolli@yahoo.com.br

\section{DIEGO VILANOVA RODRIGUES}

Mestrando no Programa de Pós-graduação em Educação da Universidade Estadual de Campinas. Professor do Ensino Fundamental na Rede Municipal de Ensino de Sumaré e Orientador Pedagógico na Rede Municipal de Ensino de Campinas. Campinas/SP - Brasil.vilanovarodrigues@ gmail.com

Submetido em: 12-8-2016

Aceito em: 2-2-2017 